\title{
Mass transfer in packed beds at low Peclet numbers - wrong experiments or wrong interpretations?
}

\author{
G. Rexwinkel,* A. B. M. Heesink and W. P. M. Van Swaaij \\ Department of Chemical Engineering. Twente University of Technology. PO Box 217.7500 AE \\ Enschedc. The Netherlands
}

(Accepted 7 July 1997)

\begin{abstract}
Much research has been focused on mass transfer phenomena in packed beds. For Peclet numbers above 200 , empirical relations have been derived that predict the value of the mass transfer coefficient as a function of the Reynolds number and the Schmidt number. These relations are more or less similar to the well-known relation that Ranz and Marshall derived for mass transfer around a single sphere in an infinite medium

$$
S h=x+\beta R{ }^{\prime} \cdot S{ }^{\prime \prime} .
$$

For packed beds of spherical particles an $x$-value of 3.89 can be calculated on basis of fundamental considerations. However. Sherwood numbers much lower than this minimum value have been observed at Peclet numbers below 100 . Several explanations have been proposed for this apparent discrepancy. such as misinterpretation of the experimental results due to unjustified neglection of axial dispersion or wall channeling. In this work, a model that predicts the combined effects of axial dispersion and wall channeling has been developed. With this model, it is possible to explain the results obtained with undiluted beds in which all particles are active in the process of mass transfer. However, such an explanation is not possible for the results obtained with diluted beds in which not all particles are active. Therefore, in the case of diluted beds other reasons for the apparent drop in mass transfer rate must exist. In the present investigation, it is demonstrated that the drop again originates from misinterpretation of the experimental results. It is shown, both experimentally and theoretically, that low Sherwood numbers can be obtained when large differences exist between the local concentration. experienced by an active particle and the mixed cup concentration of the whole bed cross-section. $\because " 1997$ Elsevier Science L.td
\end{abstract}

Keywords: Mass transfer; packed beds: low Peclet numbers; dilution.

\section{INTRODLCTION}

The rate of mass transfer between particles and fluid in packed-bed contactors in often predicted with the help of a generalized, dimensionless correlation

$$
S h=\text { function }(R e, S c, \text { Geometry). }
$$

Several correlations have been published. e.g. by Wakao and Funazkri (1978) and Gnielinski (1978). Most of these were based on mass transfer measurements performed at high Peclet numbers $(P c>200)$. and are modified versions of the well-known Ranz-Marshall equation, that was derived for a single sphere in an infinite medium. Though these correlations are accurate at high Peclet numbers. at low

*Corresponding author. Tel.: 00315,34894338 : fax: 00315348944774
Peclet numbers $(P e<100)$ Sherwood numbers have been measured that are less than predicted. Sce Fig. 1. in which the results of several studies are presented.

Sorensen and Stewart (1974) examined mass transfer in packed beds on a fundamental basis. They demonstrated that. at low Reynolds numbers $\left(R_{e}<10\right)$. the rate of mass transfer is only a function of the Peclet number. They also showed that the minimum value of the Sherwood number, which is reached at $P e=0$. amounts to 3.89 in the case of ideally packed spherical particles. A similar result was obtained by Gunn (1978). Up to now, this result could not be confirmed experimentally, not even when applying shallow beds to minimize experimental inaccuracies, that are inevitable due to two complications that appear when operating at low Peclet numbers: (i) the number of mass transfer units becomes quite large. making it difficult to determine the driving force for mass transfer in an accuratc way, and (ii) the 


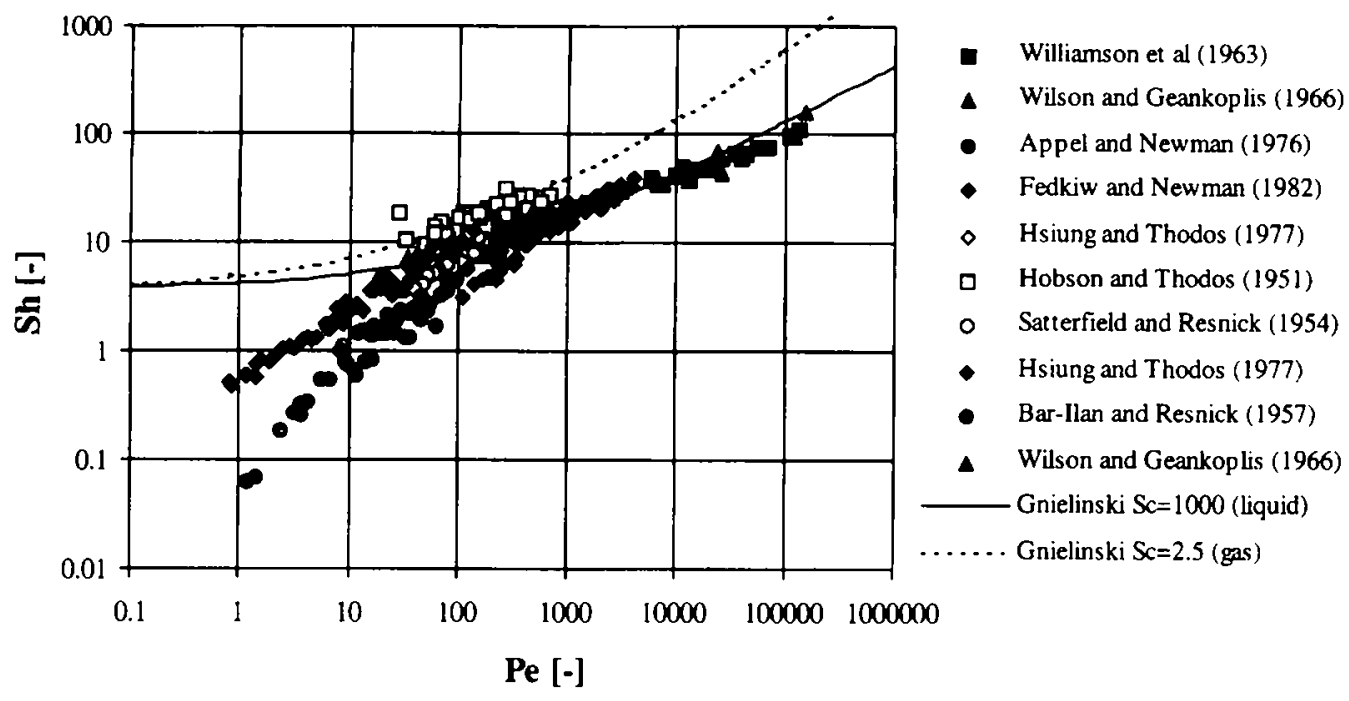

Fig. 1. Experimental Sherwood numbers from literature. Black symbols: undiluted bed-liquid; White symbols; undiluted bed-gas; Gray symbols: diluted bed-gas (Bar-Ilan and Resnick, 1957; Hsiung and Thodos. 1977) and diluted bed-liquid (Wilson and Geankoplis, 1966).

contribution of free convection to total mass transfer may become significant. In order to overcome the first complication some researchers applied diluted beds in which only a part of the particles is active in the mass transfer process, e.g. Bar-Ilan and Resnick (1957), Wilson and Geankoplis (1966) and Hsiung and Thodos (1977). By doing so they could lower the concentration in the effluent and calculate the driving force for mass transfer more precisely. Nevertheless, their results are still not in accordance with expectations on basis of theory, as is illustrated by Fig. 1. The correlation proposed by Gnielinski is assumed to describe the actual Sherwood number satisfactorily for the whole Peclet range, since it predicts a limiting Sherwood number of 3.8 at zero flow, which is in agreement with the theoretical findings of Sarensen and Stewart (1974), while at higher Peclet numbers this correlation has also proven to be accurate.

In this paper, we will demonstrate that the discrepancy between measured and predicted Sherwood numbers, which is observed at low Peclet numbers, is caused by wrong calculation of the (local) driving force for mass transfer. We will do so both for undiluted beds, in which all particles are active, and for diluted beds, in which only part of the particles in active. However, emphasis will be on diluted beds. It will be shown that such beds need a completely different approach than undiluted beds, and that the results obtained with diluted beds are of no value to those interested in mass transfer phenomena in undiluted beds, at low Peclet numbers.

\section{RE-EVALUATION OF EXPERIMENTAL DATA}

Most Sherwood numbers, that were reported in literature, where calculated while assuming plug flow behavior of the fluid flowing through the bed, i.e. while neglecting the effects of axial dispersion and wall channeling. This may not always be justified, especially not at small Peclet numbers. For example, in the case of shallow beds, axial dispersion may have a significant negative effect on the average driving force for mass transfer, causing an apparent drop in Sherwood number as was illustrated by Wakao and Funazkri (1978). In the case of small diameter beds, wall channeling may result in overestimation of the average driving force in the bed, also resulting in an apparent drop in Sherwood number (Martin, 1978).

As most reported data were obtained from measurements that were carried out with shallow beds with a small diameter, it makes sense to re-evaluate these data while correcting for the influences of axial dispersion and wall channeling. We did so with the help of the model developed by Martin (1978), which was expanded in the following ways:

- Mass transfer is assumed also to occur in the wall zone. The mass transfer coefficients in the wall zone and in the center part of the bed are assumed to be equal.

- The fluid concentrations in the effluents from both zones are calculated on the basis of the axially dispersed plug-flow model, in a similar way as was done by Wakao and Funazkri (1978). The gas dispersion coefficient is calculated with a correlation proposed by Gunn (1987), whereas the liquid dispersion coefficient was calculated using a correlation of Chung and Wen (1968) These correlations have been proven to be accurate also at low Peclet numbers.

The results of the re-evaluation are shown in Fig. 2. It appears that, in the case of undiluted beds, the reevaluated Sherwood numbers reasonably agree with 


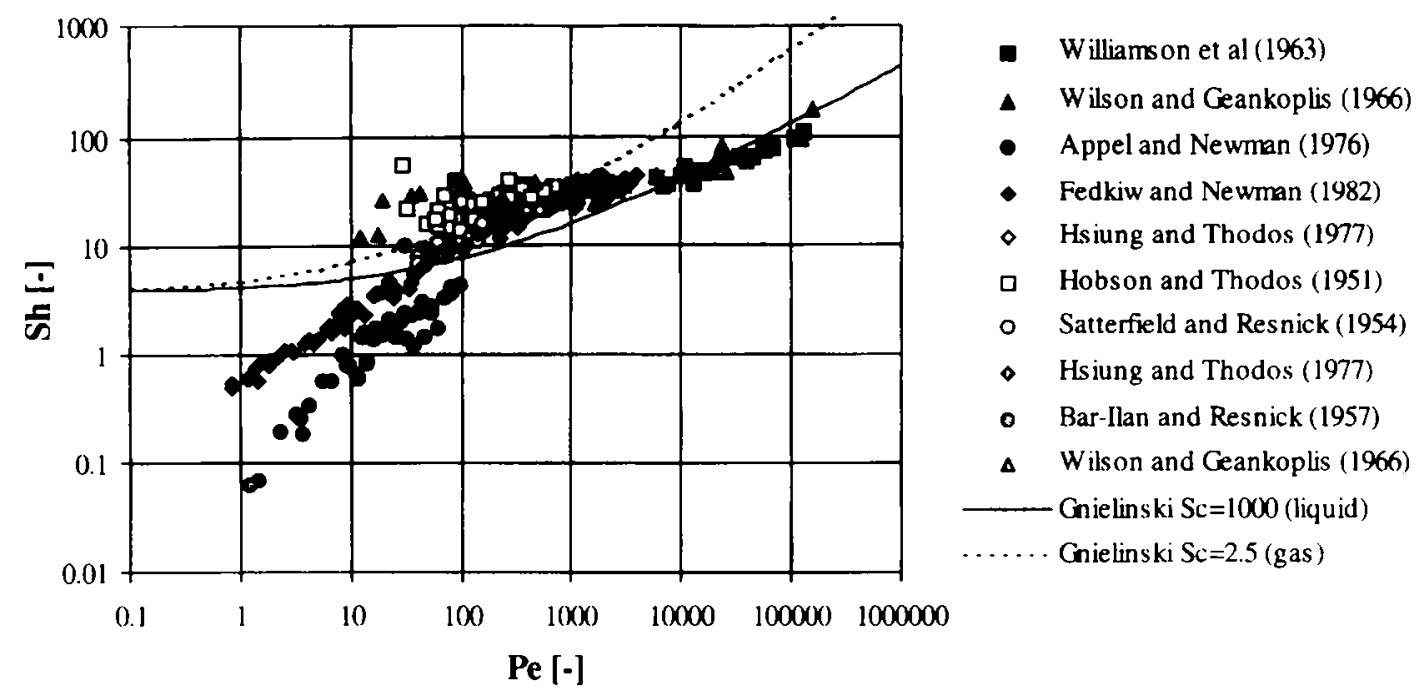

Fig. 2. Re-evaluated Sherwood numbers. Black symbols: undiluted bed-liquid: White symbols: undiluted bed -gas: Gray symbols: diluted bed gas (Bar-Ilan and Resnick, 1957; Hsiung and Thodos. 1977) and diluted bed liquid (Wilson and Geankoplis. 1966).

theory. Apparently, the drop in Sherwood number. that is observed in undiluted beds at decreasing Peclet number, is caused by wrong interpretation of the experimental results, i.e. by unjustified neglection of axial dispersion and or wall channeling.

Re-evaluation hardly has an effect on the data obtained with diluted beds. We therefore conclude that, in the case of diluted beds, other phenomena than axial dispersion or wall channeling cause the drop in Sherwood number which is observed at decreasing Peclet number. Below, we will try to identify these phenomena. We start with a study of a single active particle surrounded by inactive particles only. Then. we will examine beds containing multiple active particles.

\section{DILI TED BEDS: A SINGLE ACTIVE PARTICLE}

\subsection{Theoreticul}

Ranz and Marshall (1952) examined mass transfer around a single sphere located in an infinite medium, in which no other particles are present. They showed in a simple way that the minimum value of the Sherwood number (at $P e=0$ ) amounts to 2 . In the case that the sphere is located in an infinite bed of inactive particles the value of the minimum Sherwood number is by definition obtained by multiplying this value of 2 with the porosity $\varepsilon$ of the bed and by dividing it by the tortuosity $\tau$ of the bed:

$$
S h_{\min }=\stackrel{i}{\tau} 2
$$

The tortuosity of a randomly packed bed can be calculated according to (Puncochar and Drahos.
1993):

$$
\tau=\frac{1}{\sqrt{\varepsilon}}
$$

yielding. $S h_{\min }=2 \varepsilon^{1.5}$. This is in agreement with the results obtained by Miyauchi (1971). The minimal value thus amounts to about 0.5 which is lower than the minimal value predicted for undiluted beds, in which the concentration profile around a particle does not reach beyond the neighboring particles.

\subsection{Experimental}

Solid-gas mass transfer coefficients of a single active sphere in an inactive bed have been determined by measuring the evaporation rate of a camphor sphere with a purity $96 \%$ and a diameter of $1 \mathrm{~cm}$ in a nitrogen gas stream. A camphor sphere was weighed before the experiment and subsequently placed inside the center of a regularly packed bed of $1 \mathrm{~cm}$ diameter glass spheres, having a diameter of $10.5 \mathrm{~cm}$ and a height of $12 \mathrm{~cm}$ [Fig. 3(a)]. Before entering the packed bed, the nitrogen gas was led through a distributor with a height of $6 \mathrm{~cm}$, consisting of glass beads of $1 \mathrm{~mm}$. in order to ensure an evenly distributed gas flow. After a certain time of operation, during which the gas flow was directed either upflow or downflow through the bed, the camphor sphere was weighed again. From the change in mass the mass transfer coefficient was calculated:

$$
k=-\frac{m_{0}-m_{t_{\mathrm{cos}}}}{t_{\mathrm{exp}} \pi d_{p}^{2}\left(C_{\mathrm{s}}-C_{b}\right) M} .
$$

In a first experiment a camphor sphere was weighed, placed inside the packed bed and after a while. not applying a nitrogen gas stream, taken out of the bed 


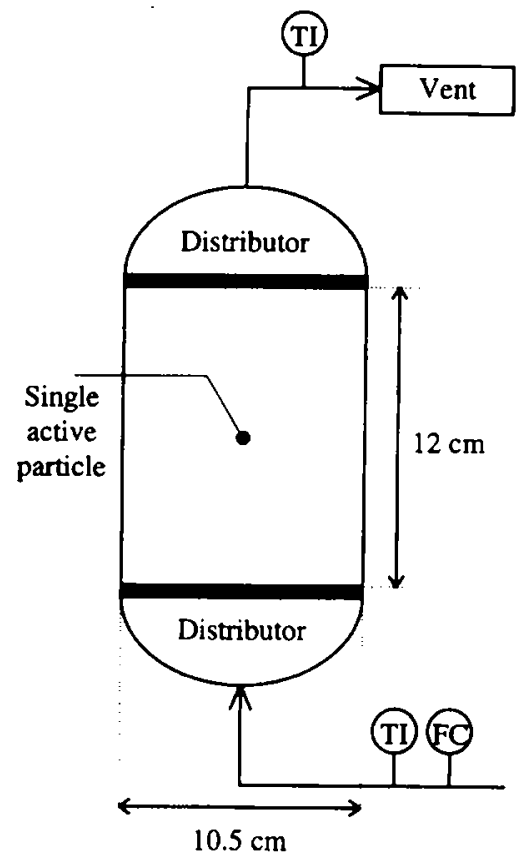

a)

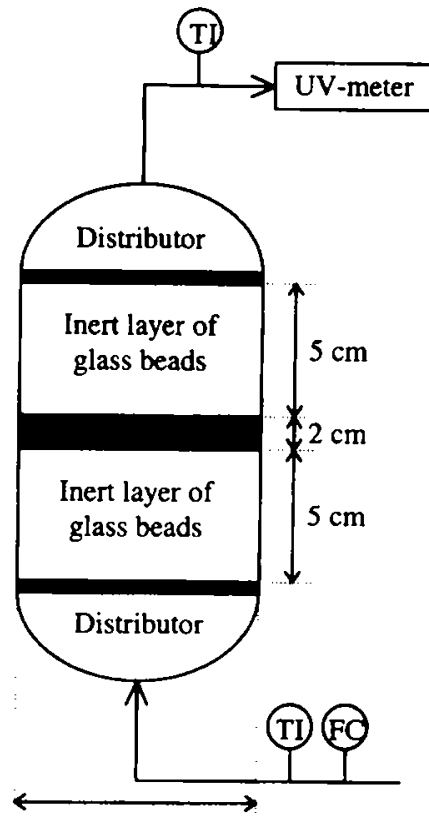

$10.5 \mathrm{~cm}$

b)

Fig. 3. Schematic of the experimental setup for two different types of experimens: (a) Single active sphere in an inactive packed bed of glass spheres; (b) Multiple active spheres in a bed of inactive glass spheres which is located between two layers of inactive glass spheres.

Table 1. Physical properties (at $25^{\circ} \mathrm{C}$ ) together with design data and operating conditions applied during the experiments

\begin{tabular}{lcc}
\hline & $\begin{array}{c}\text { Single active } \\
\text { particle }\end{array}$ & $\begin{array}{c}\text { Multiple active } \\
\text { particles }\end{array}$ \\
\hline Transferred species & $\begin{array}{c}\text { Camphor } \\
\text { Nitrogen gas } \\
\text { Fluid }\end{array}$ & $\begin{array}{c}\text { Methylbenzoate } \\
\text { Water }\end{array}$ \\
Temperature & $20-25 \mathrm{C}$ & $20-25 \mathrm{C}$ \\
Molecular mass of transferred species & $0.15224 \mathrm{~kg} / \mathrm{mol}$ & $0.13615 \mathrm{~kg} / \mathrm{mol}$ \\
Diffusion coefficient of transferred species & $6.2 \times 10^{-6} \mathrm{~m} / \mathrm{s}^{*}$ & $9.3 \times 10^{-10} \mathrm{~m}^{2} / \mathrm{s}^{*}$ \\
Solubility of transferred species &.- & $2.15 \mathrm{~g} / \mathrm{l}^{:}$ \\
Vapor pressure of transferred species & $30.2 \mathrm{~Pa}$ & -- \\
Particle diameter & $10 \mathrm{~mm}$ & $0.63-0.71 \mathrm{~mm}$ \\
Bed porosity & $0.40 \pm 0.01$ & $0.40 \pm 0.01$ \\
Percentage active particles & - & $0.35 \%$ \\
Sc & 2.54 & 1099 \\
Re & $0.11-141$ & $0.001-1$ \\
\hline
\end{tabular}

*Yaws (1995); 'Wilke and Chang (1955); 'Getzen et al. (1992); 'Presser (1972)

and weighed again. It appeared that the reduction of mass during this experiment could be neglected compared to the reduction observed after a normal experiment of several hours. During all experiments the decrease in particle diameter was negligible whereas the increase of the camphor concentration in the nitrogen stream was small. Therefore, the bulk concentration, $C_{b}$, could be considered equal to zero. The saturation concentration, $C_{s}$, was determined from the ideal gas law and the camphor vapor pressure,
$P_{\text {vap }}$, that was calculated for the applied temperature, which varied between 20 and $25^{\circ} \mathrm{C}$ but remained constant during a single experiment. With these data and the data from Table 1 available, the Sherwood number was calculated according to

$$
S h=\frac{R T\left(m_{0}-m_{t_{\mathrm{csp}}}\right)}{t_{\text {cxp }} \pi d_{p} P_{\text {vap }} M D} .
$$

In Fig. 4, the experimentally obtained Sherwood numbers are plotted versus the Peclet number. The 
solid line in this figure represents the correlation proposed by Ranz and Marshall (1952). The upflow and downflow experiments gave equal results indicating that the influence of free convection on the mass transfer rate can be neglected. Below a Peclet number of 50 the presence of inert particles becomes noticeable causing the measured Sherwood number of fall below the value predicted by the Ranz Marshall equation. At very low Peclet numbers the Sherwood number indeed approaches the theoretical minimum of approximately 0.5 . which is lower than the minimal value of 3.89 in undiluted beds. We may thus conclude that diluted beds cannot be used to examine mass transfer phenomena in undiluted beds at low Peclet numbers. We also conclude that the drop in Sherwood number to values below the limit of 0.5 . as observed with diluted beds, e.g. Bar-Ilan and Resnick (1953), must be caused by interaction of the active particles present in the diluted bed. We will examine this possible interaction in the next section.

\section{DILL"TED BEDS: MI I.TIPIE ACTIVE PARTICI.ES}

\subsection{Theoretical}

As has been stated earlier. it is important to know the local driving force for mass transfer in order to be able to calculate the local mass transfer coefficient. In

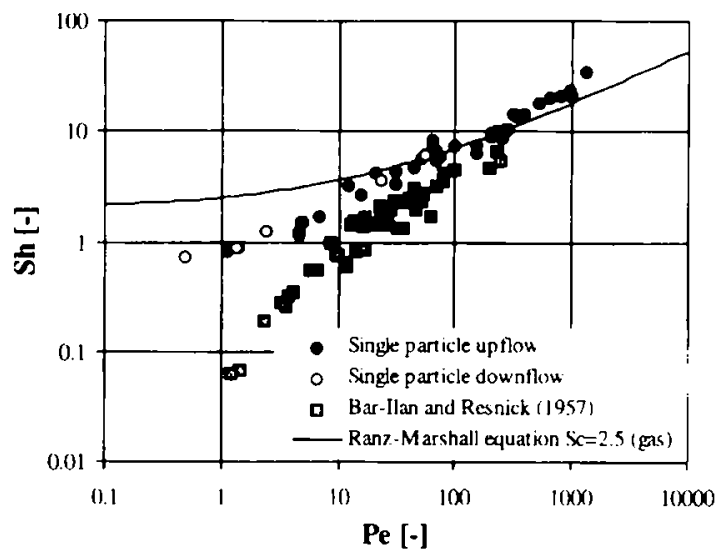

Fig. 4. Fxperimental Sherwood numbers for a single active particle together with the results of multiple active particles of Bar-Ilan and Resnick (1957). the case of a single active sphere in an infinite bed of inert particles, the driving force for mass transfer experienced by the active particle in exactly known and trivial. Determination of the driving force experienced by an individual active particle in a diluted packed bed. in which more active particles are present. is less trivial.

In Fig. 5. several hypothetical distributions of active particles in a two-dimensional packed bed are shown. The driving force experienced by the active particles will be much different in each situation. In situation I all active particles experience the same driving force which has not been influenced by the presence of any active particles upstream. In situation II all active particles have been placed directly on top of each other. The influence of particles upstream on the driving force experienced by the particles downstream will be significant. The average mass transfer rate in situation II will therefore be lower than the average mass transfer rate in situation I. In situation III the active particles have also been placed on top of each other. but now inactive particles are placed in between. In this situation the average mass transfer rate will also be lower than in situation $I$, but higher than in situation II due to the extra radial dispersion of the transferred species. Although the particle distributions shown in Fig. 5 are rather exceptional, they do indicate that the average rate of mass transfer will be overestimated if it is assumed that no radial concentration gradients occur.

\subsection{Experimental}

The spread in experimental results obtained with diluted beds at low Peclet numbers is considerable. Hsiung and Thodos (1977) in their diluted packed bed observed only slightly lower Shewood numbers than the values found for a single sphere. whereas Bar-Ilan and Resnick (1957) have measured much lower Sherwood numbers. Since the cause for this spread is unknown. we also carried out some experiments in diluted packed beds. Mass transfer experiments were conducted by measuring the dissolution rate of methylbenzoate in water. Methylbenzoate was impregnated in spherical porous Amberlite XAD-2 particles with an average diameter $0.66 \mathrm{~mm}$. In all experiments $0.5 \mathrm{~g}$ of impregnated particles was

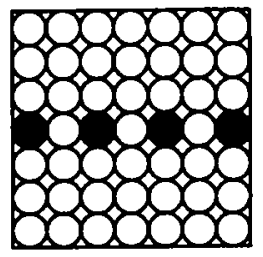

I

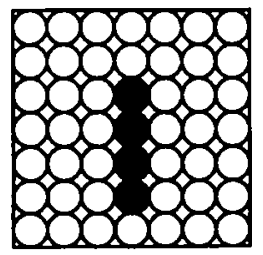

II

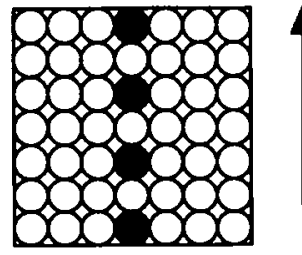

III

\section{Direction of flow}

Active particles

Fig. 5. Several hypothetical distributions of active particles in a two-dimensional packed bed. 
thoroughly mixed with spherical glass particles of the same size. The mixture, of which $0.35 \%$ of all particles was active, was brought into the bed resulting in an active layer of $2 \mathrm{~cm}$ high. This layer was enclosed by two $5 \mathrm{~cm}$ thick layers of inert glass beads. See Fig. 3 (b). The methylbenzoate concentration at the exit of the packed bed was continuously measured using an UV-spectrophotometer. The methylbenzoate concentration in the effluent remained constant during the first hour of operation, indicating that pore limitation in the porous Amberlite XAD- 2 particles could be neglected. The Sherwood numbers were calculated by assuming plug-flow behavior

$$
S h=-\frac{d_{p}^{2} \Phi_{V} \rho_{p}}{6 D m_{p}} \ln \left(\frac{C_{S}-C_{\text {out }}}{C_{S}-C_{\text {in }}}\right) .
$$

The results are shown in Fig. 6 and are similar to those of Bar-Ilan and Resnick (1957): Much smaller values are obtained than with a single active particle.

In order to confirm that these smaller Sherwood numbers are found because of interaction between the different active particles in the bed, extra experiments were performed. These were done at a fixed Peclet number of 2.89 using $0.5 \mathrm{~g}$ of impregnated Amberlite XAD-2 particles. The number of mass transfer units was thus kept constant. The height of the bed, including the inert layers at the bottom and the top, always was $12 \mathrm{~cm}$. In order to simulate situation I of Fig. 5 all active particles were positioned in a horizontal layer which was enlosed by two layers of inert glass beds having the same diameter of $0.66 \mathrm{~mm}$ as the active particles. In this way about $20 \%$ of the bed crosssection was covered with active particles. Situation III of Fig. 5 was also simulated. First all active particles were mixed with equally sized inert glass beads. The obtained mixture was then dumped into a tube with a diameter of $1.35 \mathrm{~cm}$ and a height of $8 \mathrm{~cm}$, which was placed in the center of the bed, which was already filled with a $2 \mathrm{~cm}$ thick layer of inert glass beads. Next, the annular space in between the tube and the bed wall was filled with inert glass beads and the tube was slowly removed. Finally, a $2 \mathrm{~cm}$ thick layer of inert

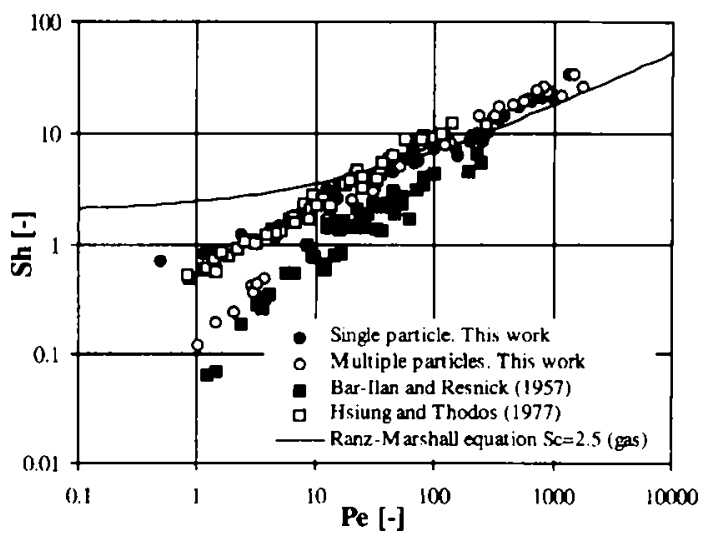

Fig. 6. Experimental Sherwood numbers for single particle and multiple particles in a diluted bed. glass beads was added to complete the bed. Additional to these experiments, tests were performed using diluted layers of varying thickness [according to the set-up shown in Fig. 3(b)]. By applying a constant amount of impregnated Amberlite XAD-2 particles of $0.5 \mathrm{~g}$, the degree of dilution was varied. The results of the interaction experiments were evaluated on basis of eq. (6). The calculated Sherwood numbers are shown in Fig. 7.

If the assumption of a radially well-mixed fluid would hold in all cases, all experiments should have given the same result, since equal amounts of active particles have been applied. However, the results show a significant influence of the particle distribution, which is in conflict with this assumption. The calculated Sherwood numbers appear to increase when the fraction of active particles is decreased, especially at high degrees of dilution. This is in accordance with expectations, since the average axial distance between the active particles strongly depends on the degree of dilution at high dilution degrees, whereas this dependence is relatively small at lower degrees of dilution. So, the extent of radial mixing will increase with the degree of dilution, in particular at high degrees of dilution. The results obtained with the particle distributions resembling situations I and III of Fig. 5 also confirm that interaction between active particles is an important item in diluted beds. This interaction, which results from radial concentration profiles, is not accounted for when assuming plugflow behavior. We will illustrate this with the model discussed below.

\subsection{The model}

The importance of radial concentration profiles and the resulting interaction between different active particles in the bed can also be demonstrated in a theoretical way. To do so, the diluted bed is modelled by a two-dimensional network of interconnected continuously stirred tank reactors (CSTR); see Fig. 8. Each CSTR contains exactly one particle which is

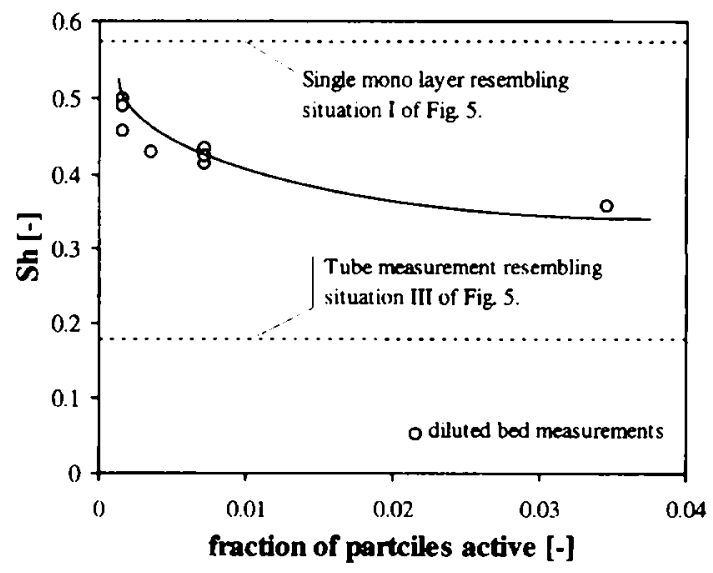

Fig. 7. Experimental Sherwood numbers for several distributions of active particle over the bed. $P e=2.89 ; S c=1099$. 


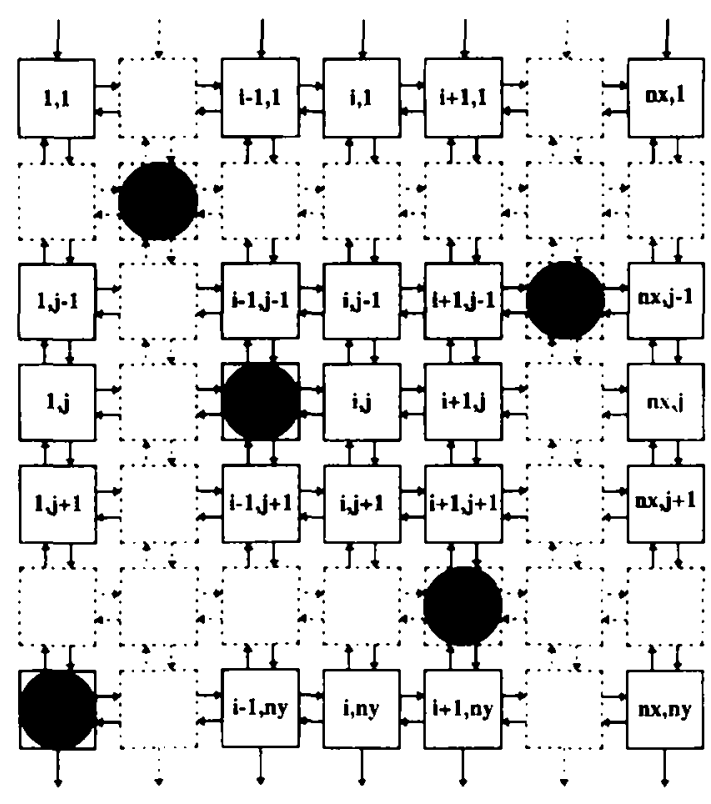

Fig. 8. Schematic representation of the interconnected CSTRs model where the grey dots represent active particles: Flowdirection is downward. $n x=$ number of particles in horizontal direction and $n y=$ number of particles in vertical direction.

either active or inactive. Whether a particle is active or not is randomly determined. A somewhat similar approach was applied by van den Bleek (1969), who investigated the effect of dilution on the degree of conversion in fixed-bed catalytic reactors.

Mass transfer between CSTRs takes place in axial direction through convection and axial dispersion and in lateral direction by dispersion. The amount of material transferred by dispersion between two neighboring CSTRs is calculated according to

$$
\begin{aligned}
& N_{i, j \rightarrow i, j+1}=-D_{\mathrm{ax}} \frac{C_{i, j+1}-C_{i, j}}{d_{p}} \\
& N_{i, j \rightarrow i-1, j}=-D_{\text {lat }} \frac{C_{i-1, j}-C_{i, j}}{d_{p}} .
\end{aligned}
$$

A stationary dimensionless mass balance for CSTR $i$. j yields

$$
\begin{aligned}
0= & \left(-1-\frac{2}{B o_{\mathrm{lat}}}-\frac{2}{B o_{\mathrm{ax}}}\right) \mathbf{C}_{i, j}+\left(1+\frac{1}{B o_{\mathrm{ax}}}\right) \mathbf{C}_{i, j} 1 \\
& +\frac{1}{B o_{\mathrm{ax}}} \mathbf{C}_{i, j+1}+\frac{1}{B o_{\mathrm{la} 1}} \mathbf{C}_{i-1, j} \\
& +\frac{1}{B o_{\mathrm{Iat}}} \mathrm{C}_{i+1, j}+n_{a}^{i, j} \frac{\pi}{i} \frac{S h}{P e}\left(\Delta \mathbf{C}_{i, j}\right) .
\end{aligned}
$$

With $\mathbf{C}_{i, j}$ defined as $C_{i, j} / C_{s}, C_{s}$ being the concentration at the surface of an active particle which is either dissolving or evaporating. In this equation $n_{a}^{i, j}$ can adapt the values 0 or 1 and indicates whether or not an active particle is present in CSTR $i, j$. The CSTRs that are located against the packed-bed wall are only connected to CSTRs in the interior of the bed.

An important term is $\Delta \mathbf{C}_{i, j}$. which represents the driving force experienced by an active particle in $\operatorname{CSTR} i, j$. In the case of undiluted beds this driving force should by definition be based on the mixed cup concentration of the whole bed cross-section. However, it is not to be expected that the same definition holds for diluted beds because of radial concentration gradients. As we are interested in demonstrating the effects of neglecting these radial concentration gradients, in the present model two definitions of driving force are applied: (i) mixed cup driving force, which is calculated from the mixed cup concentration in a horizontal row, and (ii) CSTR driving force, which is calculated on basis of the concentration within the CSTR in which the active particle is located. In mathematical form

$$
\Delta \mathbf{C}_{t, j}=1-\sum_{i}^{n x} \frac{\mathbf{C}_{i . j}}{n x}
$$

or

$$
\Delta \mathbf{C}_{i, j}=1-\mathbf{C}_{i, j}
$$

Equation (8) has been solved using both expressions for the driving force by the successive over relaxation method. As it makes no sense to apply expressions that were derived for three-dimensional beds and that predict a final value of Sherwood at $P e=0$, the Sherwood number was calculated somewhat arbitrarily according to

$$
S h=0.3 P e^{1 \cdot 3} .
$$

The values of $B o_{\text {lat }}$ and $B o_{3 x}$ were calculated from correlations reported by Gunn (1987). Figure 9 shows the calculated lateral concentration profiles at the exit of a packed bed. containing $200 \times 40$ particles with a diameter of $0.5 \mathrm{~mm}$ of which 300 are active, using the two different definitions of driving force.

Figure 9 clearly shows that large lateral concentration gradients may exist in diluted packed beds. Furthermore, it shows that neglecting these lateral concentration gradients, which is done when calculating the local driving force for mass transfer according to eq. (9a), can result in local dimensionless concentrations which are larger than unity, which by definition is impossible. The local driving force for mass transfer in a diluted bed is thus overestimated when the radial concentration profile in the bed is neglected, as is done when the plug-flow model is applied to evaluate the experimental results. This is also illustrated by Fig. 10 in which the predicted Sherwood number is shown as a function of the Peclet number for both definitions of the local driving force $\Delta \mathbf{C}_{i, j}$. The presented Sherwood numbers were calculated while assuming plug-flow behavior of the fluid. which is common practice when evaluating mass transfer experiments

$$
S h=\cdots \frac{n x}{n_{\text {active }}} \frac{\delta}{\pi} P_{e} \ln \left(1-\frac{\sum_{i \cdot 1}^{n x} \mathbf{C}_{i, n y}}{n x}\right) .
$$



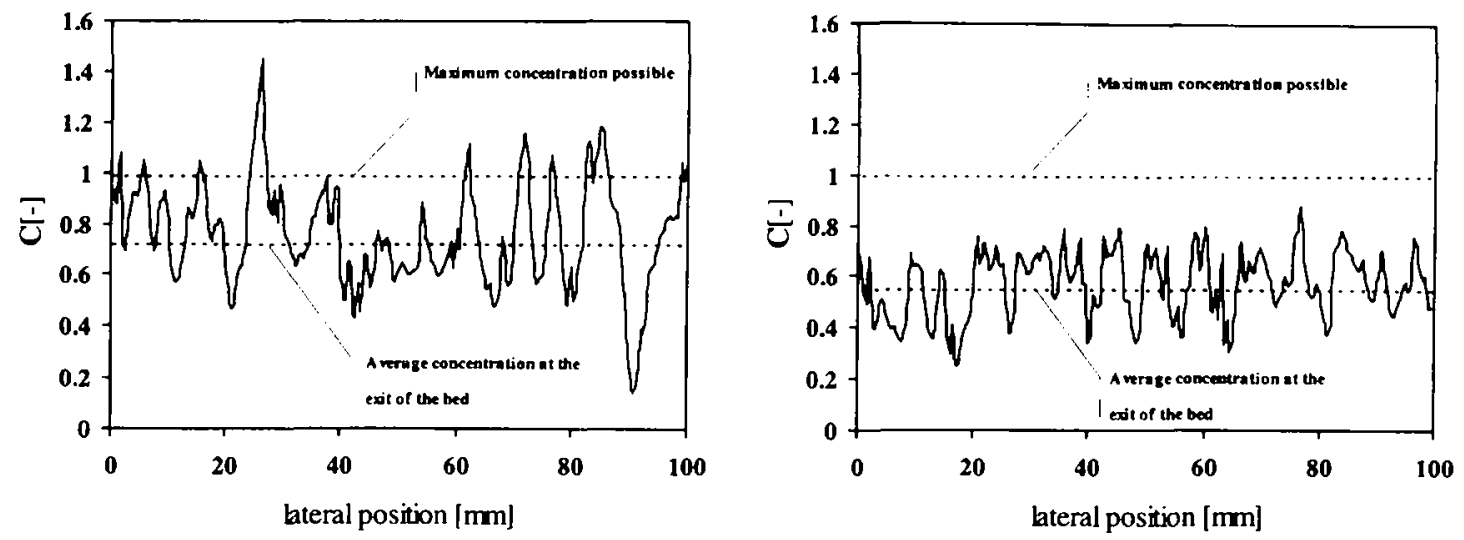

Fig. 9. Calculated radial concentration profiles at the exit of the packed bed: (a) Mixed up driving force:

(b) CSTR driving force. $P e=10 ; S h=1.5 ; B o_{1 \mathrm{at}}=10 ; B o_{\mathrm{ax}}=4 ; \quad d_{\mathrm{r}}=0.5 \mathrm{~mm} ; n x=200 ; n y=40$ : $n_{\text {active }}=300 ; i=0.48=1-\pi: 6$.

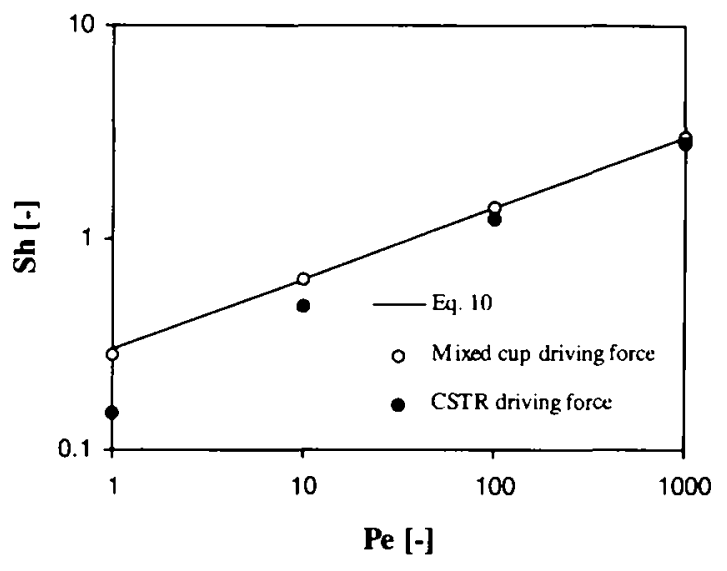

Fig. 10. Sherwood numbers calculated using eq. (11) from the mixed cup concentration at the exit of the bed as calculated by the interconnected CSTR model using the two different definitions of the driving force. $S c=1000$; $d_{p}=0.5 \mathrm{~mm} ; n x=2(0): n y=40 ; n_{\text {aclive }}=300: \varepsilon=0.48$.

The values obtained when calculating the driving force on basis of the mixed cup concentration are almost equal to those predicted by eq. (10). (Only the value at $P e=1$ is somewhat less due to axial dispersion which is included in the model.) The values obtained when calculating the driving force on basis of the CSTR-concentration are much lower. We, therefore, conclude that the deviation between measured and predicted Sherwood number, which is observed in diluted beds at low Peclet numbers, is, at least partly, caused by the neglection of radial concentration profiles inside the bed.

Due to its simplicity. the present model is not suited to quantify the effects of radial concentration profiles on the average rate of mass transfer inside a diluted bed. For this. CFD simulations are necessary.

\section{CONCLUSIONS}

The deviation between predicted and reported Sherwood numbers in packed beds at low Peclet numbers is caused by the wrong interpretation of the experimental data. In the case of undiluted beds corrections should be made for axial dispersion and wall channeling. The Sherwood numbers when obtained reasonably agree with theory. Such corrections do not suffice in the case of diluted beds. The minimal Sherwood number in diluted beds is lower than in undiluted beds. Furthermore. in diluted beds the existence of radial concentration profiles should be considered, which is not possible when the distribution of the active particles is random and therefore not exactly known. Neglection of these radial concentration profiles by applying of the plug-flow model results in underestimated Sherwood numbers. Therefore. diluted beds should not be used to examine mass transfer phenomena in undiluted beds at low Peclet numbers.

\section{Acknowledgements}

This investigation was supported by the Dutch Ministry of Fconomic Affairs. The authors acknowledge J. Görten and J. M. Meerdink for their assistance in the experimental work.

\section{NOTATION}

C concentration of transferred species in the fluid, $\mathrm{mol} / \mathrm{m}^{3}$

C dimensionless concentration $C / C_{s}$, dimensionless

$\Delta \mathbf{C}_{i, j}$ driving force experienced by an active particle in CSTR $i, j$, dimensionless

$d_{p} \quad$ particle diameter, $\mathrm{m}$

D diffusion coefficient of transferred species. $\mathrm{m}^{2} / \mathrm{s}$

$D_{\mathrm{ax}} \quad$ axial dispersion coefficient, $\mathrm{m}^{2} / \mathrm{s}$

$D_{\text {lat }} \quad$ lateral dispersion coefficient, $\mathrm{m}^{2} / \mathrm{s}$ 
$k$ mass transfer coefficient, $\mathrm{m} / \mathrm{s}$

$m \quad$ mass, $\mathrm{kg}$

$M \quad$ molecular mass, $\mathrm{kg} / \mathrm{mol}$

$n_{a}^{i . j} \quad$ random factor ( 0 or 1 ) of eq. 8 , dimensionless

$n_{\text {active }} \quad$ number of active particles, dimensionless

$n x$ number of particles in horizontal direction, dimensionless

ny number of particles in vertical direction, dimensionless

$N \quad$ flux, molim $\mathrm{m}^{2} \mathrm{~s}$

$P_{\text {vap }} \quad$ vapor pressure of camphor, $\mathrm{Pa}$

$R \quad$ gas constant, $\mathrm{J} / \mathrm{molK}$

$t_{\exp }$ duration of experiment, $\mathrm{s}$

$T$ temperature, $\mathrm{K}$

i interstitial fluid velocity, $\mathrm{m} / \mathrm{s}$

\section{Greek letters}

$\begin{array}{ll}\varepsilon & \text { bed porosity, dimensionless } \\ \eta & \text { viscosity, } \mathrm{Pa} \mathrm{s} \\ \Phi_{V} & \text { fluid flow, } \mathrm{m}^{3} \text { s } \\ \rho & \text { density, } \mathrm{kg} / \mathrm{m}^{3} \\ \tau & \text { tortuosity, dimensionless }\end{array}$

Subscripts
$\begin{array}{ll}\text { min } & \text { minimal } \\ 0 & \text { initially } \\ b & \text { in the bulk } \\ f & \text { with respect to fluid } \\ i & \text { radial position of CSTR } \\ \text { in } & \text { at the inlet } \\ i & \text { axial position of CSTR } \\ \text { out } & \text { at the outlet } \\ p & \text { with respect to particle(s) } \\ s & \text { saturation }\end{array}$

Dimensionless numbers

$B o_{a x} \quad$ axial Bodenstein number $\left(=v d_{p} / D_{\mathrm{ax}}\right)$

$B o_{\text {lat }}$ lateral Bodenstein number $\left(=t: d_{p} / D_{\text {lat }}\right)$

Sh Sherwood number $\left(=k d_{p} / D\right)$

$P e \quad$ interstitial Peclet number $\left(=v d_{p} / D\right)$

Re Reynolds number $\left(=\rho_{f} v d_{p} / \eta_{s}\right)$

Sc $\quad$ Schmidt number $\left(=\eta_{f} / \rho_{f} D\right)$

\section{REFERENCES}

Appel, P. W. and Newman, J. (1976) Application of the limiting current method to mass transfer in packed beds at very low Reynolds numbers. A.I.Ch.E. J. 22, 979-984.

Bar-Ilan, M. and Resnick, W. (1957) Gas phase mass transfer in fixed beds at low Reynolds numbers. Ind. Engng Chem. 49, 313-320.

Bleek van den, C. M., Wiele van der, $K$. and Berg van den, P. J. (1969) The effect of dilution on the degree of conversion in fixed bed catalytic reactors. Chem. Engng Sci. 24, 681-694.
Chung. S. F. and Wen, C. Y. (1968) Longitudinal dispersion of liquid flowing through fixed and fluidized beds. A.I.Ch.E. J. 14,857-866.

Fedkiw, P. S. and Newman, J. (1982) Mass-transfer coefficients in packed beds at very low Reynolds number. Int. J. Heat Mass Transfer 25, 935-943.

Getzen. F.. Hefter, G. and Maczynski, A. (1992) Solubility Data Series, Vol. 48. Pergamon Press, Oxford.

Gnielinski, V. (1978) Gleichungen zur Berechnung des Wärme- und Stoffaustauches in durchströmten ruhenden Kugelschüttungen bei mittleren und grossen Pecletzahlen. VT-verfahrenstechnik 12. 363--366.

Gunn. D. J. (1978) Transfer of heat or mass to particles in fixed and fluidised beds. Int. J. Heat Mass Transfer 21, 467476.

Gunn. D. J. (1987) Axial and radial dispersion in fixed beds. Chem. Engng Sci. 42, 363-373.

Hobson, M. and Thodos, G. (1951) Laminar flow of gases through granular beds. Chem. Engng Prog. 47. 370375 .

Hsiung. T. H. and Thodos, G. (1977) Mass-transfer factors from actual driving forces for the flow of gases through packed beds $\left(0.1<R c^{\prime}<100\right)$. Int. J. Heat Mass Transfer 20, $331-340$.

Martin, H. (1978) Low Peclet number particle-to-fluid heat and mass transfer in packed beds. Chem. Engng Sci. 33, 913-919.

Miyauchi. T. (1971) Film coefficients of mass transfer of dilute sphere-packed beds in low flow rate regime. J. Chem. Engng Japan 4, 238245.

Presser. K. H. (1972) Die Stofübertragung fest-gasförmig bei laminarer freier Knovection. Wärme- und Stoffübertragung 5. 220-228.

Puncochar, M. and Drahos, J. (1993) The tortuosity concept in fixed and fluidized bed. Chem. Engng Sci. 48, 21732175.

Ranz, W. E. and Marshall, W. R. Jr (1952) Evaporation from drops. Part I. Chem. Engng Prog. 48. 141-146.

Satterfield, C. N. and Resnick, H. (1954) Simultaneous heat and mass transfer in a diffusion-controlled chemical reaction. Chem. Engng Prog. 50, 504510.

Sorensen, J. P. and Stewart. M. E. (1974) Computation of forced convection in slow flow through ducts and packed beds-III. Heat and mass transfer in a simple cubic array of spheres. Chem. Engng Sci. 29. 827832 .

Wakao, N. and Funazkri, T. (1978) Effect of fluid dispersion coefficients on particle-to-fluid mass transfer coefficients in packed beds. Chem. Engny Sci. 33, $1375 \cdot 1384$.

Wilke. C. R. and Chang, P. (1995) Correlation of diffusion coefficients in dilute solutions. A.I.Ch.E.J. 1, 264-270.

Williamson, J. E., Bazaire, K. E. and Geankoplis, C. J. (1963) Liquid-phase mass transfer at low Reynolds numbers. Ind. Enyng Chem. Fund. 2, 126-129.

Wilson, E. J. and Geankoplis, C. J. (1966) Liquid mass transfer at very low Reynolds numbers in packed beds. Ind. Engny Chem. Fundam. 5. 914

Yaws, C. L. (1995) Handook of Transport Property Data. Gulf Publishing company, Houston. 